\section{Increased serum concentrations of advanced glycation end products: a marker of coronary artery disease activity in type 2 diabetic patients}

\author{
K Kiuchi, J Nejima, T Takano, M Ohta, H Hashimoto
}

\begin{abstract}
Objective-To assess whether the concentrations of serum advanced glycation end products (AGE) in diabetic patients with obstructive coronary artery disease differ from those in type 2 diabetic patients without obstructive coronary artery disease.

Design-Serum AGE concentrations were measured in type 2 diabetic patients and in non-diabetic patients, both with and without obstructive coronary artery disease, and the relation between these values and coronary disease severity was evaluated.

Results-Mean (SD) serum AGE concentrations were higher $(\mathrm{p}<0.0125)$ in type 2 diabetic patients with obstructive coronary artery disease $(5.5(2.5) \mathrm{mU} / \mathrm{ml}, \mathrm{n}=30)$ than in patients without obstructive coronary artery disease $(2.8(0.5) \mathrm{mU} / \mathrm{ml}, \mathrm{n}=12)$, and higher than in nondiabetic patients with $(3.4(1.0) \mathrm{mU} / \mathrm{ml}, \mathrm{n}=28)$ and without $(3.2(0.4) \mathrm{mU} / \mathrm{ml}, \mathrm{n}=13)$ obstructive coronary artery disease. Serum AGE was associated with the degree of coronary arteriosclerosis in type 2 diabetic patients with obstructive coronary artery disease (single vessel: $\mathrm{n}=13,3.4(0.9) \mathrm{mU} / \mathrm{m}$; two vessel: $\mathrm{n}=6,5.7(1.6) \mathrm{mU} / \mathrm{m}$; three vessel: $\mathrm{n}=11,7.2(2.5) \mathrm{mU} /$ $\mathrm{ml})$. Serum AGE was positively correlated with serum mean four year $\operatorname{HbA}_{1 \mathrm{C}}(r=0.46$, $\mathrm{p}<0.01)$, but not with recent serum $\mathrm{HbA}_{1 \mathrm{C}}(r=0.24)$. The four groups did not differ in the other coronary risk factors.
\end{abstract}

Conclusions-Serum AGE concentrations may be associated with long term poor glycaemic control and reflect the severity of coronary arteriosclerosis in type 2 diabetic patients.

(Heart 2001;85:87-91)

Keywords: advanced glycation end products; non-insulin dependent diabetes; coronary artery disease
It is generally acknowledged that sustained hyperglycaemia is a major factor in the development of various complications in diabetic patients. Advanced glycation end products (AGE) are produced by a non-enzymatic reaction between proteins and sugars in patients with long term hyperglycaemia. AGE accumulate with time and are irreversibly deposited in various tissues of the body, contributing to the development of diabetic complications, arteriosclerosis, and aging. Recent studies have suggested that AGE may play a central role in the pathogenesis of diabetic vascular complications, ${ }^{1-3}$ as they lead to an abnormal leakage of proteins from the circulation and a progressive constriction of the luminal area in vessels.

Sustained hyperglycaemia leads to the accumulation of non-enzymatically derived glycation products on proteins. In this process, glucose first forms chemically reversible Amadori type early glycation products with protein. Through a series of chemical rearrangements, some of these Amadori products are converted to AGE. As these are irreversibly bound to proteins, they accumulate continuously on long lived vessel wall proteins. The rate of accumulation is proportional to the time integrated blood glucose level over long periods of time. AGE have been recognised as factors in the pathogenesis of diabetic complications, including nephropathy ${ }^{2}$ and retinopathy. $^{23}$
AGE bind to specific receptors on endothelial cells. After cellular attachment, they have been shown to increase vascular permeability, procoagulant activity, adhesion molecule expression, and monocyte influx-actions that may contribute to vascular injury. ${ }^{4}$ Thus AGE may play an important role in diabetic arteriosclerosis. However, little is known about the role of AGE in diabetic patients with coronary artery disease. Our aim in this study was thus to determine whether serum AGE concentrations correlate with coronary arteriosclerosis in diabetic patients.

\section{Methods}

PATIENTS

We studied 83 consecutive patients admitted to our coronary care unit for assessment of chest pain. All subjects were selected from consecutive patients who underwent coronary angiography in our coronary care unit because of chest pain or clinically suspected coronary artery disease. The diagnoses of stable angina and unstable angina were made on the basis of a thorough clinical examination, and obstructive coronary artery disease was verified by coronary angiography.

The study involved the following:

- type 2 diabetic patients with coronary artery disease: $\mathrm{n}=30,23$ male, seven female; nine with stable angina, 21 with unstable angina; mean (SD) age 64 (10) years; 
- type 2 diabetic patients without coronary artery disease: $\mathrm{n}=12$, nine male, three female; mean age 64 (10) years;

- non-diabetic patients with coronary artery disease: $\mathrm{n}=28,22$ male, six female; six with stable angina, 22 with unstable angina; mean age 67 (9) years;

- non-diabetic patients without coronary artery disease: $\mathrm{n}=13$, nine male, four female; mean age 66 (19) years.

Obstructive coronary artery disease was defined as a reduction of $75 \%$ or more in the luminal diameter of at least one major epicardial coronary artery, determined by coronary angiography. Eleven patients had three vessel disease, six had two vessel disease, and 13 had single vessel disease in the type 2 diabetic patients with obstructive coronary artery disease. Among the diabetic patients without significant coronary stenosis, one had coronary calcification, and one had diffuse coronary sclerosis; coronary stenosis in these patients did not reach $50 \%$ diameter reduction.

Patients with renal dysfunction (serum creatinine concentration $\geqslant 133 \mu \mathrm{mol} / \mathrm{l}$ ) and acute myocardial infarction were excluded from the study. Study subjects were classified as non-smokers if they had never smoked or had stopped smoking at least one year before cardiac catheterisation. All the other subjects were classified as smokers. Hypertension was defined as a systolic blood pressure of $>140 \mathrm{~mm} \mathrm{Hg}$ and/or a diastolic blood pressure of $>90 \mathrm{~mm} \mathrm{Hg}$. Patients were considered to have hypertension if they had been treated with antihypertensive drugs. The definition of glucose tolerance was based on a two hour $75 \mathrm{~g}$ oral glucose tolerance test according to the World Health Organization criteria. Patients were considered to have diabetes mellitus if they had been treated with antidiabetic drugs.

AGE ANALYSIS

Serum AGE was measured by a newly developed enzyme linked immunosorbent assay (ELISA) method using anti-AGE keyhole limpet haemocyanin, as previously described. ${ }^{5-7}$ AGE keyhole limpet haemocyanin (KLH, Calbiochem, California, USA) was prepared by incubating $50 \mathrm{mg} \mathrm{KLH}$ at $37^{\circ} \mathrm{C}$ for 16 weeks in $2 \mathrm{ml}$ sterile $0.4 \mathrm{M}$ phosphate buffer, $\mathrm{pH} 7.2$, containing $0.56 \mathrm{M}$ glucose. Anti-AGE antibody was raised in rabbit by immunising interdermally with AGE-KLH $(400 \mu \mathrm{g})$, emulsified with complete Freund's adjuvant, 10 times at four week intervals. Antisera obtained two weeks after the final injection were used for the assay.

A 96 well microplate (MaxiSorp, Nune, Denmark) was coated at $4^{\circ} \mathrm{C}$ overnight with $100 \mu \mathrm{l}$ of AGE-bovine serum albumin (BSA, Sigma, Missouri, USA) diluted $10^{5}$-fold with phosphate buffered saline (PBS). After washing with PBS containing $0.05 \%$ tween-20 (PBST), $100 \mu \mathrm{l}$ of diluted AGE-BSA ( $1: 10^{2}$ to $\left.1: 10^{6}\right)$ as standards, or serum samples treated as above, were added to each well. Then $100 \mu \mathrm{l}$ of anti-AGE antiserum diluted $1: 10^{4}$ was added and incubated at $4^{\circ} \mathrm{C}$ overnight. After washing with PBST, $100 \mu \mathrm{l}$ of HRP-antirabbit immunoglobulins was added to each well and incubated at $25^{\circ} \mathrm{C}$ for four hours. Also after washing with PBST, $100 \mu$ of 3,3',5,5'tetramethylbenzidine solution was added to each well and incubated for 40 minutes. The optical density was measured at $450 \mathrm{~nm}$ with a microplate ELISA reader, after the addition of $50 \mu \mathrm{l}$ of $2 \mathrm{~N} \mathrm{H}_{2} \mathrm{SO}_{4}$.

Results are expressed as arbitrary AGE units ( $1 \mathrm{mU}$ of AGE corresponds $4 \mu \mathrm{l}$ of AGE-BSA standard). Our antibody did not cross react with Amadori products but did cross react with carboxymethyl lysine, and reacted slightly with pentosidine. Values for the intra-assay coefficient of variation of our ELISA system were $4.8-10.2 \%$, and interassay values were $3.5-$ $6.2 \%$.

Venous blood samples were drawn from each subject after overnight fasting for measurement of plasma glucose, total cholesterol, triglycerides, high density lipoprotein (HDL) cholesterol, low density lipoprotein (LDL) cholesterol, uric acid, and haemoglobin $\mathrm{A}_{1 \mathrm{C}}\left(\mathrm{HbA}_{1 \mathrm{C}}\right)$. Glucose was determined by the glucose oxidase method, ${ }^{8}$ and total cholesterol, ${ }^{9}$ triglycerides, ${ }^{10}$ HDL cholesterol, ${ }^{11}$ and uric acid were determined as described previously. The LDL cholesterol concentrations were calculated according to the Friedewald equation. ${ }^{12}$ Measurements of $\mathrm{HbA}_{1 \mathrm{C}}$ were made every month for a median of four years. We calculated the average of $\mathrm{HbA}_{1 \mathrm{C}}$ values measured during this period.

\section{ANGIOGRAPHIC ANALYSIS}

Coronary angiography was carried out according to the Judkins technique, and images of the coronary tree were obtained in routine standardised projections in all patients. Two experienced cardiologists, unaware of the patients' clinical characteristics and biochemical results, reviewed all the angiographic images. The number of diseased coronary vessels was based on the number of coronary arteries showing stenosis with $\geqslant 75 \%$ reduction in lumen diameter. A patient with $50 \%$ or greater obstruction of the left main coronary artery was classified as having two vessel disease if the circulation was right dominant and three vessel disease if it was left dominant. When discrepancies arose, a third experienced observer was involved and the lesion classified by consensus.

\section{STATISTICAL METHODS}

All values were expressed as mean (SD). For multiple comparisons, Student's $t$ test with Bonferroni (Dunn) correction was used to determine significance of the differences among the four groups. Thus when three comparisons were made, a probability value of $\mathrm{p}<0.017$ was used to determine significance. Comparison of mean four year $\mathrm{HbA}_{1 \mathrm{C}}$ data between diabetic patients with and without obstructive coronary artery disease was made by Student's $t$ test for unpaired values. To identify relevant relations, linear regression analysis was applied to assess the correlation of serum AGE concentrations first with the recent $\mathrm{HbA}_{1 \mathrm{C}}$ results, and second with the mean four year $\mathrm{HbA}_{1 \mathrm{C}}$ results. 
Table 1 Clinical characteristics of the study subjects

\begin{tabular}{|c|c|c|c|c|}
\hline \multirow[b]{2}{*}{ Characteristic } & \multicolumn{2}{|l|}{$N I D D M$} & \multicolumn{2}{|c|}{ Normal glucose tolerance } \\
\hline & $\begin{array}{l}\text { Normal } \\
(n=12)\end{array}$ & $\begin{array}{l}C A D \\
(n=30)\end{array}$ & $\begin{array}{l}\text { Normal } \\
(n=13)\end{array}$ & $\begin{array}{l}C A D \\
(n=28)\end{array}$ \\
\hline Age (years) & $64(10)$ & $64(10)$ & $66(19)$ & $67(9)$ \\
\hline Sex (male/female) & $9 / 3$ & $23 / 7$ & $9 / 4$ & $22 / 6$ \\
\hline Hypertension (\%) & 67 & 73 & 69 & 71 \\
\hline Smokers $(\%)$ & 67 & 70 & 69 & 68 \\
\hline Duration of diabetes (years) & $9.1(2.9)$ & $9.3(3.4)$ & - & - \\
\hline Fasting blood sugar $(\mathrm{mmol} / \mathrm{l})$ & $9.66(3.02)$ & $9.43(3.34)$ & $5.31(0.39)$ & $5.57(0.75)$ \\
\hline $\mathrm{HbA}_{1 \mathrm{c}}(\%)$ & $8.5(1.1)$ & $8.4(1.5$ & $5.0(0.5)$ & $5.2(0.4)$ \\
\hline Mean four year $\mathrm{HbA}_{1 \mathrm{c}}(\%)$ & $8.1(0.5)$ & $9.3(0.5)$ & - & - \\
\hline Total cholesterol $(\mathrm{mmol} / \mathrm{l})$ & $5.22(0.92)$ & $5.18(0.99)$ & $5.09(0.77)$ & $5.27(0.87)$ \\
\hline LDL cholesterol (mmol/l) & $3.73(0.63)$ & $3.69(0.70)$ & $3.66(0.81)$ & $3.67(0.61)$ \\
\hline HDL cholesterol $(\mathrm{mmol} / \mathrm{l})$ & $1.24(0.33)$ & $1.24(0.31)$ & $1.27(0.57)$ & $1.33(0.31)$ \\
\hline Triglycerides $(\mathrm{mmol} / \mathrm{l})$ & $1.37(0.73)$ & $1.36(0.64)$ & $1.34(0.76)$ & $1.37(0.69)$ \\
\hline Uric acid $(\mu \mathrm{mol} / \mathrm{l})$ & $310(89)$ & $313(92)$ & $321(85)$ & $326(79)$ \\
\hline Microalbuminuria (with/without) & $3 / 9$ & $7 / 23$ & - & - \\
\hline
\end{tabular}

Values are mean (SD) or $\mathrm{n}$

CAD, coronary artery disease; NIDDM, non-insulin dependent diabetes mellitus.

\section{Results}

CHARACTERISTICS OF THE STUDY GROUPS

The clinical characteristics of the study subjects are shown in table 1 . No statistical differences were observed for age, sex, or the proportion of hypertensive subjects and smokers among the four groups. The four groups did not differ in the serum concentrations of total cholesterol, LDL cholesterol, HDL cholesterol, triglycerides, and uric acid. The fasting serum glucose and $\mathrm{HbA}_{1 \mathrm{C}}$ concentrations were significantly higher in the diabetic groups than in the non-diabetic groups. There were no differences between diabetic patients with and without obstructive coronary artery disease with respect to fasting serum glucose and recent $\mathrm{HbA}_{1 \mathrm{C}}$.

RELATION BETWEEN SERUM AGE AND HBA $1 \mathrm{C}$ The serum concentrations of AGE were positively correlated with serum mean four year $\mathrm{HbA}_{1 \mathrm{C}}(r=0.46, \mathrm{p}<0.01)$ but not with recent serum $\mathrm{HbA}_{1 \mathrm{C}}(r=0.24)$ (fig 1 ).

SERUM AGE AND CORONARY ARTERIOSCLEROSIS Serum AGE was significantly higher in the diabetic patients with obstructive coronary artery disease $(5.5(2.5) \mathrm{mU} / \mathrm{ml})$ than in those without $(2.8(0.5) \mathrm{mU} / \mathrm{ml})$, and it was also higher than in non-diabetic patients with and
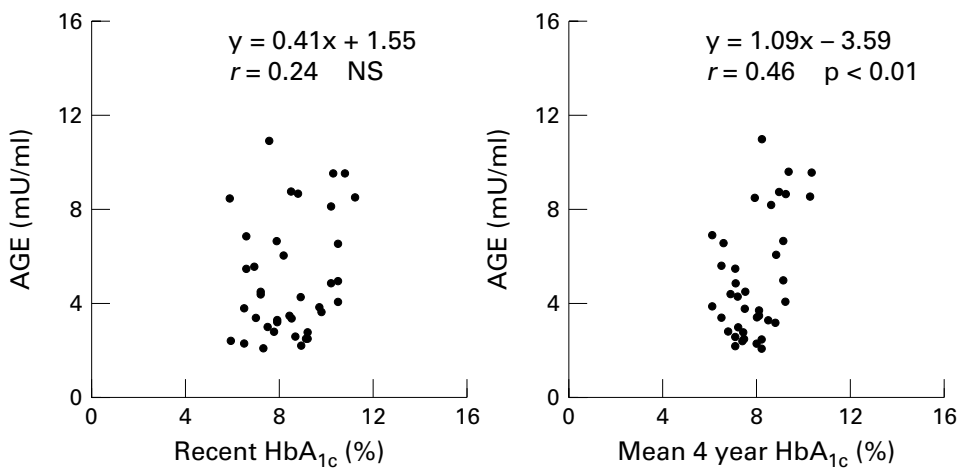

Figure 1 Scatterplot showing relation between $A G E$ and recent $H b A_{1 C}$ (left), and mean four year $\mathrm{HbA}_{1 C}$ (right). Recent $\mathrm{Hb} \mathrm{A}_{1 \mathrm{C}}$ was not correlated with serum $A G E$, whereas there was a significant but weak correlation between mean four year $\mathrm{Hb} A_{1 C}$ and serum $A G E$ $(r=0.46, p<0.01)$.

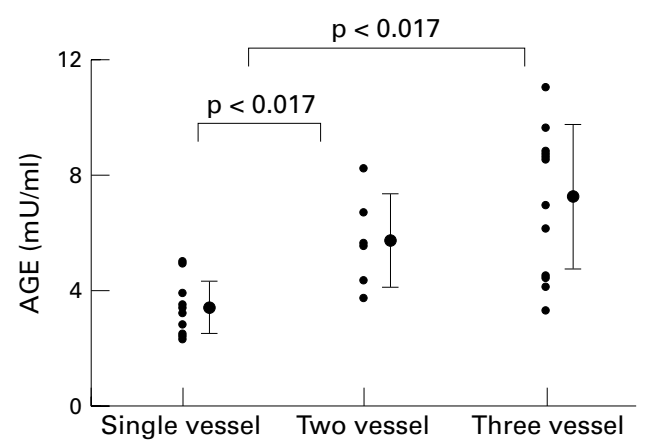

Figure 2 Serum AGE concentrations and the severity of coronary arteriosclerosis in the diabetic patients with obstructive coronary artery disease. Serum AGE increased with the severity of coronary arteriosclerosis in the diabetic patients with obstructive coronary artery disease.

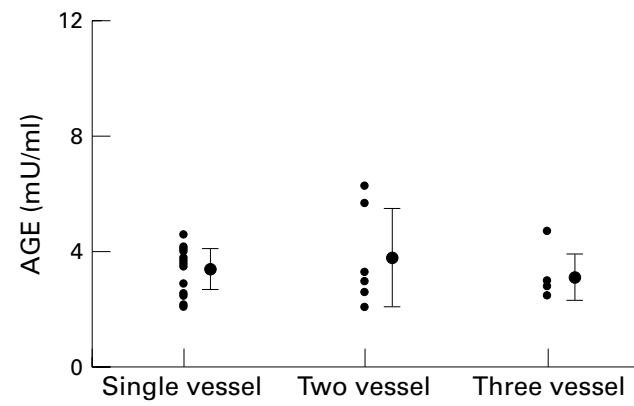

Figure 3 Serum AGE concentrations and the severity of coronary arteriosclerosis in the non-diabetic patients with obstructive coronary artery disease. Serum AGE did not increase in these patients and did not correlate with the severity of the coronary arteriosclerosis.

without obstructive coronary artery disease (3.4 (1.0) and $3.2(0.4) \mathrm{mU} / \mathrm{ml}$, respectively). Serum AGE increased with the severity of coronary arteriosclerosis in the diabetic patients with obstructive coronary artery disease: single vessel disease: $\mathrm{n}=13,3.4(0.9) \mathrm{mU} / \mathrm{ml}$; two vessel disease: $\mathrm{n}=6,5.7(1.6) \mathrm{mU} / \mathrm{ml}$; three vessel disease: $\mathrm{n}=11,7.2$ (2.5) $\mathrm{mU} / \mathrm{ml}$ (fig 2). AGE values were not increased in the nondiabetic patients with obstructive coronary artery disease and did not correlate with disease severity: single vessel disease: $\mathrm{n}=16$, $3.4(0.7) \mathrm{mU} / \mathrm{ml}$; two vessel disease: $\mathrm{n}=6,3.8$ (1.7) $\mathrm{mU} / \mathrm{ml}$; three vessel disease: $\mathrm{n}=6,3.1$ (0.8) $\mathrm{mU} / \mathrm{ml}$ ) (fig 3).

\section{Discussion}

Incubating proteins with glucose leads, through early products such as Schiff's base and Amadori adducts, to advanced glycation end products. This is referred to as the Maillard reaction. Several investigations have emphasised an important role of AGE in the pathogenesis of diabetic complications. ${ }^{1-3}$ Makita and colleagues showed that concentrations of AGE peptides increased in accordance with the severity of diabetic nephropathy. ${ }^{2}$ Ono and colleagues reported that serum AGE concentrations in diabetic patients with proliferative retinopathy were significantly higher than in patients without retinopathy. ${ }^{3} \mathrm{Re}-$ cently, Kilhovd and associates found that serum AGE was increased in patients with 
type 2 diabetes with coronary heart disease. ${ }^{13}$ Thus AGE may play an important role in the development of macrovascular disease as well as microvascular disease in patients with diabetes.

Our major finding in the present investigation was that serum AGE reflected the severity of coronary arteriosclerosis in diabetic patients, independent of other coronary risk factors, including hyperlipidaemia, hypertension, hyperuricaemia, and smoking. It is important to note that serum AGE did not increase in the non-diabetic patients with obstructive coronary artery disease. These results may indicate a role for AGE in the development of macrovascular disease in patients with type 2 diabetes. Hyperglycaemia seems to be associated with increased coronary artery disease. In addition, diabetic patients who have poor glycaemic control also have higher AGE concentrations. Thus the finding that serum AGE in diabetic patients with more severe coronary artery disease is higher than in diabetic patients without coronary disease is hardly surprising. The fact that there was no difference in serum AGE between patients with type 2 diabetes and non-diabetic controls in the absence of coronary artery disease probably reflects the difference in long term glycaemic control. Interestingly, we found serum concentrations of AGE to be correlated with mean four year $\mathrm{HbA}_{1 \mathrm{C}}$ but not with recent $\mathrm{HbA}_{1 \mathrm{C}}$ measurements. This suggests that long term poor glycaemic control is related to AGE production.

The mechanism whereby serum AGE concentrations reflect the development of coronary arteriosclerosis in diabetic patients is unclear. There may be several possible mechanisms for AGE involvement in the macrovascular complications of diabetes. AGE bind to specific receptors on endothelial cells, and they can quench nitric oxide and may impair endothelial function. ${ }^{14}$ In addition, AGE are capable - through interaction with receptors-of increasing concentrations of $\mathrm{NF}-\kappa \mathrm{B}$, a transcription factor which is thought to be involved in the development of atherosclerosis. ${ }^{15}$ Furthermore, AGE activates monocytes. Monocytes/macrophages express AGE specific receptors which mediate endocytosis and the degradation of AGE modified proteins. ${ }^{16}$ Monocytes secrete growth promoting cytokines such as tumour necrosis factor, interleukin 1, and insulin-like growth factor 1 . Infiltration of the arterial subendothelial intima by macrophages/monocytes and production of cytokines may cause an abnormal leakage of proteins from the circulation and a progressive constriction of the luminal area in vessels, ${ }^{17}$ and may finally lead to the development of atheromatous lesions. Recently, Sun and colleagues examined AGE accumulation and AGE receptor expression in the aorta and heart of rats with streptozotocin induced diabetes. ${ }^{18}$ AGE deposition increased in the aorta and myocardial vessels, depending on the period of hyperglycaemia. AGE receptor was expressed in the endothelial and vascular smooth muscle cells. Thus AGE accumulation may initiate diabetic macroangiopathy through AGE receptors, and the increase in $\mathrm{AGE}$ receptor expression by endothelial cells could be a reason why atherosclerosis is accelerated in diabetes.

Another mechanism whereby serum AGE concentrations reflect the severity of coronary arteriosclerosis in diabetic patients may involve the modification of LDL as a result of glycation. It has been proposed that oxidation of the lipid component of LDL plays a central role in the pathogenesis of atherosclerosis. Recently, Bucala and colleagues showed that circulating concentrations of oxidised LDL were raised and correlated significantly with lipid AGE concentrations in diabetic patients. ${ }^{19}$ Thus AGE may be involved in the production of oxidised LDL which could also be implicated in the development of coronary arteriosclerosis.

In summary, serum AGE concentrations may be a marker of risk in type 2 diabetic patients with coronary arteriosclerosis, and serum AGE concentrations reflect the severity of the coronary artery disease.

We gratefully acknowledge Minoru Ohtake MD for helpful discussions.

1 Brownlee M, Cerami A, Vlassara H. Advanced glycosylation end products in tissue and the biochemical basis of diabetic complications. N Engl f Med 1988;318:1315-21.

2 Makita Z, Radoff S, Rayfield EJ, et al. Advanced glycosylation end products in patients with diabetic nephropathy. N Engl f Med 1991;325:836-42.

3 Ono Y, Aoki S, Ohnishi K, et al. Increased serum levels of advanced glycation end products in NIDDM patients with diabetic complications. Diabetes Care 1998;21:1027.

4 Renard C, Shappey O, Wautier MP, et al. Recombinant advanced glycation end product receptor pharmacokinetics in normal and diabetic rats. Mol Pharmacol 1997;52: $54-62$.

5 Nakayama H, Taneda S, Kuwajima S, et al. Production and characterization of antibodies to advanced glycation products on proteins. Biochem Biophys Res Commun 1989;162: $740-5$.

6 Berg TJ, Bangstad H-J, Torjesen PA, et al. Advanced glycation end products in serum predict changes in the kidney morphology of patient with insulin-dependent diabetes mellitus. Metabolism 1997;46:661-5.

7 Makita Z, Vlassara H, Cerami A, et al. Immunochemical detection of advanced glycosylation end products in vivo. $\mathcal{F}$ Biol Chem 1992;267:5133-8.

8 Hoffman WS. A rapid photoelectric method for the determination of glucose in blood and urine. $7 \mathrm{Biol}$ Chem 1937;120:52-5

9 Richmond W. Preparation and properties of a cholesterol oxidase from Nacardia $\mathrm{sp}$ and its application to the enzymatic assay of total cholesterol in serum. Clin Chem 1973;19:1350-6.

10 Fletcher MJ. A colorimetric method of estimating serum triglycerides. Clin Chim Acta 1968;22:393-7.

11 Didez LI. Separation and quantitation of subclasses of human plasma high density lipoproteins by a single precipitation procedure. F Lipid Res 1982;23:120623.

12 Friedewald WT, Levy RI, Fredrickson DS. Estimation of the concentration of low-density lipoprotein cholesterol in plasma, without use of the preparative ultracentrifuge. Clin Chem 1972;18:499-502.

13 Kilhovd BK, Thorsby P, Berg TJ, et al. Serum levels of advanced glycation end products are increased in patients with type 2 diabetes and coronary heart disease. Diabetes Care 1999;22:1543-8.

14 Bucala R, Tracey KJ, Cerami A. Advanced glycosylation products quench nitric oxide and mediate defective endothelium-dependent vasodilatation in experimental diabetes. F Clin Invest 1991;87:432-8.

15 Bierhaus A, Chevion S, Chevion M, et al. Advanced glycation end product-induced activation of NF- $\mathrm{KB}$ is suppressed by $\alpha$-lipoic acid in cultured endothelial cells. Diabetes 1997;46:1481-90. 
16 Kirstein M, Brett J, Radoff S, et al. Advanced protein glycosylation induces transendothelial human monocyte chemotaxis and secretion of platelet-derived growth factor: role in vascular disease of diabetes and aging. Proc Natl Acad Sci USA 1990;87:9010-14

17 Hasegawa G, Nakano K, Sawada M, et al. Possible role of tumor necrosis factor and interleukin-1 in the development of diabetic nephropathy. Kidney Int 1991;40:1007-12.

18 Sun $M$, Yokoyama $M$, Ishiwata $T$, et al. Deposition of advanced glycation end products (AGE) and expression of the receptor for $\mathrm{AGE}$ in cardiovascular tissue of the diabetic rat. Int $\mathcal{F}$ Exp Pathol 1998;79:207-22.

19 Bucala R, Makita Z, Koschinsky T, et al. Lipid advanced glycosylation: pathway for lipid oxidation in vivo. Proc Nat Acad Sci USA 1993;90:6434-8.

\section{Commentary}

Advanced glycation end products (AGEs) are derivatives formed by chemical reaction between glucose and proteins, resulting in extensive cross linking. AGEs have physical and biological properties that are very different to those of the parent proteins. AGEs are detected in various tissues and in serum, and their production in diabetes is regarded as a marker of long term glycaemic control. The generation of AGEs in the vasculature, or the action of circulating AGEs on endothelial receptors, is hypothesised to accentuate the development of microvascular and macrovascular complications, including nephropathy and atherosclerotic disease, in people with diabetes. However, the cellular mechanisms of vascular damage by AGEs are unknown. This report confirms the association between epicardial coronary disease and circulating concentration of AGEs in type II diabetes. Furthermore, in type II diabetes the extent of coronary disease was related to the serum AGEs concentration. No such relation was observed in non-diabetic patients with coronary disease. It should be noted that the study examined a Japanese cohort and that serum lipids were similar in diabetic and non-diabetic patients. Whether the intriguing association between AGEs concentrations and the severity of coronary disease reflects causality remains to be seen.

G F BAXTER Associate Editor

\section{IMAGES IN CARDIOLOGY}

\section{Left ventricular pacing via the great cardiac vein in a patient with tricuspid and pulmonary valve replacement}

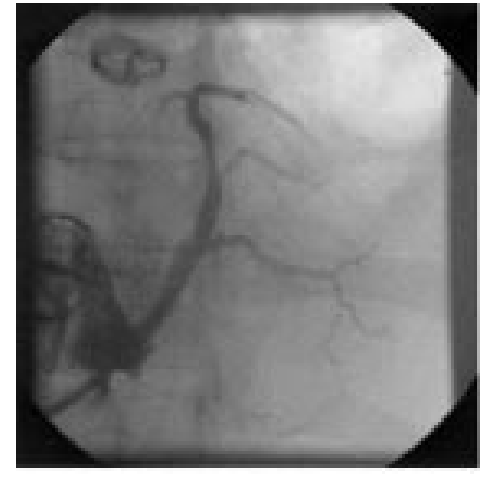

Venogram in LAO view

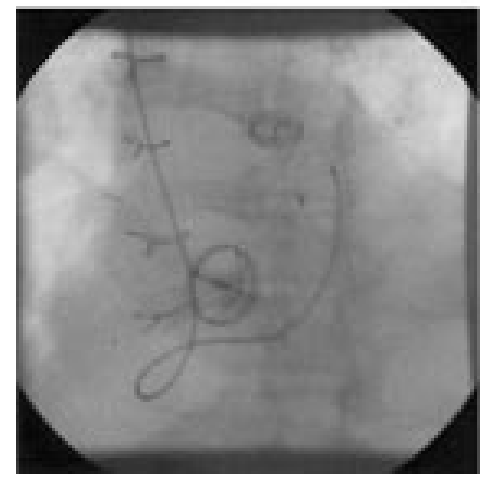

Coronary sinus lead in LAO view

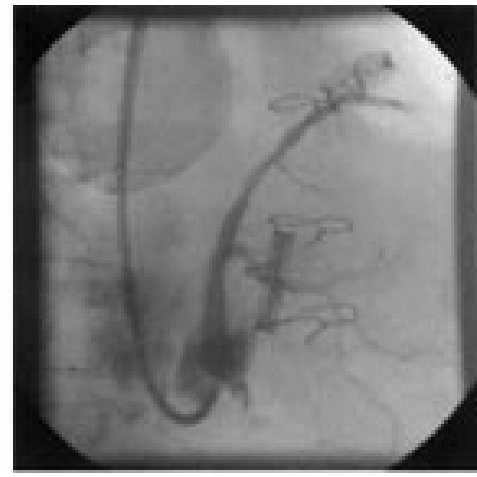

Venogram in RAO view

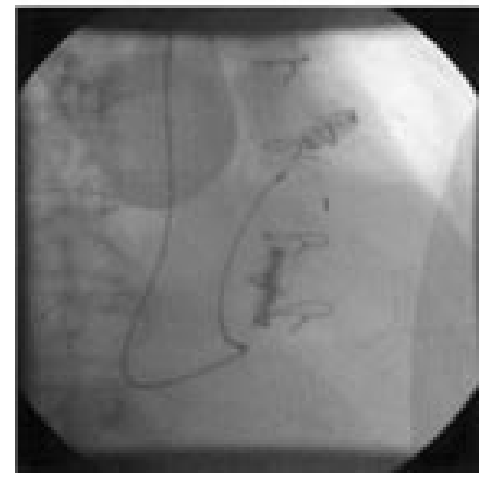

Coronary sinus lead in RAO view
A 63 year old female patient with carcinoid syndrome developed intermittent atrial flutter with complete heart block shortly after having a tricuspid and pulmonary valve replacement. Since both valves had been replaced by a Medtronic Hall mechanical tilting disc valve, it was not possible to insert a pacing lead into the right ventricle. Therefore, a unipolar, polyurethane coronary sinus lead was placed into the coronary sinus. After accessing the left cephalic vein, a guide catheter was introduced and placed into the ostium of the coronary sinus with the help of a movable tip ablation electrode. Then a venogram of the coronary veins was performed and the anatomy of the great coronary veins established. The pacing lead was inserted into the posterolateral cardiac vein. Fixation of the coronary sinus lead was achieved by angulation of the lead which occurred once the stylet was removed. Measurements at implant were: threshold at $0.5 \mathrm{~ms}$ was $0.4 \mathrm{~V}$; R wave $17.1 \mathrm{mV}$; impedance at $5 \mathrm{~V}$ was $565 \Omega$.

The atrial lead was not implanted because of fears that electrode manipulation would displace the ventricular lead. A VVIR pacemaker was implanted and programmed to VVIR at 80-90 ppm.

A pacing check three days and two months post-implant showed low threshold, good $\mathrm{R}$ wave sensing, and stable impedance.

RUTH ALTMIKS ANTHONY W NATHAN 